Décadrages Décadrages

cınéma, à travers champs Cinéma, à travers champs

$7 \mid 2006$

Stephen Dwoskin

\title{
Trois documentaires mythologisants
}

\section{Raphaël Pasche}

\section{(2) OpenEdition}

\section{Journals}

Édition électronique

URL : http://journals.openedition.org/decadrages/473

DOI : $10.4000 /$ decadrages. 473

ISSN : 2297-5977

\section{Éditeur}

Association Décadrages

\section{Édition imprimée}

Date de publication : 10 avril 2006

Pagination : 115-116

ISBN : 978-29700582-3-6

ISSN : 2235-7823

Référence électronique

Raphaël Pasche, «Trois documentaires mythologisants », Décadrages [En ligne], 7 | 2006, mis en ligne le 30 janvier 2014, consulté le 03 mai 2019. URL : http://journals.openedition.org/decadrages/473 ; DOI : $10.4000 /$ decadrages. 473

Ce document a été généré automatiquement le 3 mai 2019.

(B) Décadrages 


\title{
Trois documentaires mythologisants
}

\author{
Raphaël Pasche
}

1 Le mythe de la réussite sur fond de valeurs suisses traverse les trois documentaires Jo Siffert Live Fast - Die Young de Men Lereida, Marc Forster de Fritz Muri et Swiss Made in Hollywood de Xavier Ruiz. Le pilote automobile Joseph Siffert semble être a priori une icône originale dans le paysage helvétique, tout comme le cinéaste Marc Forster, auteur en 2004 du blockbuster hollywoodien, Finding Never Land. Quant aux trois jeunes Suisses partis tenter leur chance à Hollywood dont le film de Xavier Ruiz suit le parcours, ils sont tout aussi éloignés du cliché helvétique de la réussite financière (le modèle du banquier), du moins en apparence. Car en définitive l'excentricité des trajectoires n'est pas suffisante pour permettre au film de se démarquer des représentations canoniques.

Les discours tenus par les personnalités et les proches auxquels ces trois films donnent la parole mettent en avant les valeurs de travail, de volonté et de sacrifice comme clé du succès. Autant de conceptions qui collent à l'idéologie suisse de la réussite. C'est à force de discipline et de labeur que les trois jeunes résidents de Los Angeles espèrent percer. C'est aussi la recette qui aurait permis à Joseph Siffert de devenir l'un des plus grands pilotes automobile de son temps. Tous les témoignages rassemblés ne font que soutenir de façon réitérée cette thèse. Issu d'un milieu pauvre, Siffert serait même allé jusqu'à jeûner pour économiser l'argent nécessaire à l'achat de ses pneus. Mais la discipline à elle seule ne suffit pas à engendrer les grandes destinées : les trois films font donc intervenir la composante du risque. Or si le film de Lareida glorifie l'attitude du coureur automobile qui s'expose à un danger inconsidéré, les deux autres documentaires insistent au contraire sur l'idée d'une prise de risque avisée et calculée. Dans Swiss Made in Hollywood, le financement des études de cinéma aux Etats-Unis est envisagé comme un placement, les intéressés étant comparés à des actions boursières qui rapporteront à moyen terme. Les banquiers ne sont pas loin!

3 Le discours très stéréotypé des intervenants ne serait finalement pas excessivement gênant si les films proposaient une mise à distance, ou s'ils optaient véritablement pour un positionnement. Or la forme de ces documentaires, lorsqu'elle ne se fait pas 
ouvertement l'expression d'une adhésion à l'idéologie de la gloire médiatique, procède d'une acceptation tacite de ladite idéologie. La seconde femme de Siffert, qui revendique un rapport à l'homme plutôt qu'à l'«image publique», aura de la peine à se faire entendre. Ces trois films qui touchent à la représentation d'icônes souffrent d'une absence totale d'interrogation sur l'image. Tous jouent la carte du rapprochement émotionnel avec les stars (ou stars en puissance) auxquelles ils s'intéressent. Par conséquent, en se terminant sur les larmes des proches qui pleurent le pilote devant les caméras trente ans après son décès, Jo Siffert attribue au spectateur une place ambiguë. En effet, si l'émotion des intervenants est due au lien d'amitié qui les unissait à l'homme, celle du spectateur ne peut être, quant à elle, liée qu'au mythe, c'est-à-dire à la représentation idéalisée de Siffert. Le film de Lareida affiche d'ailleurs le parti pris d'adopter l'insouciance du personnage à travers une B.o. funky.

Pour les films Marc Forster et Swiss Made in Hollywood, l'exacerbation sans autre forme de questionnement du pathos attaché à ces mythes (actuels ou potentiels) est d'autant plus étonnante que leur thématique touche précisément au rêve hollywoodien et donc, inévitablement, à la représentation médiatique. De par son sujet, Swiss Made in Hollywood est le seul des trois documentaires dans lequel les intervenants font preuve d'incertitudes face aux rêves de grandeurs qu'ils tentent de réaliser. Mais la modération de ce discours est balayée par les choix esthétiques de Xavier Ruiz. Sur fond d'une musique rythmée et d'un montage rapide qui tient du vidéoclip, une voix off à la diction décidée commente le parcours des trois personnages, rappelant la facture racoleuse des mini reportages TV de prime time.

5 Si les documentaires de Lareida, Ruiz et Muri fonctionnent bien au niveau de leur impact émotionnel, leur intérêt nous semble cependant limité. Il est en effet regrettable que ces films n'offrent pas de véritable réflexion - au sens d'une représentation « réflexive » - sur le rapport existant entre le mythe et le cinéma.

Jo Siffert Live Fast - Die Young (2005). Réal. : Men Lareida. Scénario : M. Lareida, R. Bauman. Image : P. Corradi. Montage : M. Welter, M. Flury.

Son : O. Jean Richard, L. Yersin. Musique : N. Maeschi. Production : Hugofilm Productions.

Swiss Made in Hollywood (2005). Réal. et scénario : Xavier Ruiz. Image : N. Petsilas. Montage : V. Perriaz. Son : F. Wolf. Production : Navarro Films, TSR

Marc Forster (2005). Réal. et scénario : Fritz Muri. Image : H. Witschi. Montage : E.Bleicher. Son : P. Schertenleib, T. Klunke. Musique : Suisa. Production : Schweizer Fernsehen. 